\section{Clinital allectures}

\section{INFANTILE PARALYSIS AND ITS RESULTING DEFORMTTIES.}

\author{
Bx RICHARD BARWELL, F.R.C.S., \\ SURGEON TO CHARING-CROSS HOSPITAL.
}

\section{LECTURE VII.}

OF all deformities arising from paralysis of children, those of the foot are the most varied, and to the philosophical anatomist the most interesting. All the four conditions classed under the names varus, valgus, equinus, and calcaneus appear, as do their intermediates described by mingling together two of the above names; as, for instance, equinovarus, \&c. Besides this, two other distortions-namely, flatfoot and pes cavus - are frequently met with. I have had occasion often to point out the fact, that the power which maintains any limb in normal position is muscular force, not ligamentous resistance; and that when the former fails, the latter yields so readily and rapidly as clearly to show how little mere ligament is adapted to withstand any prolonged strain. This is especially exemplified in the foot, which, bearing the full weight of the body, is more than any other part exposed to the frequent effect of considerable pressure. Thus if the surgeon rotate outwards the valgous foot of a child, certain of whose muscles are paralysed, he will find every joint of the tarsus extremely loose in that direction, but quite unyielding to the contrary movement. Especially will his attention be directed to the calcaneo-scaphoid joint, which is so lax on the inner side as to permit the foot, including the heel, to be twisted almost directly outwards, and this without any change in the position of the astragalus at the ankle-joint. In varus the medio-tarsal joint is that which is chiefly affected, yielding very readily to inward rotation and adduction, but not at all in the contrary direction. Both these instances show that the unsupported ligaments or the unsupported portion of a ligament will yield as a secondary consequence of muscular debility or paralysis.

In practice it is of importance that we should distinguish between two sets of cases: the one, in which a certain muscle or a certain group of muscles is paralysed, and in which the deformity is produced by the unopposed action of the sound organs; the other, in which all muscles have been paralysed, and none have gained sufficient power to deflex the limb, deformity, if present, being produced by position, the muscles on the shortened side hardening themselves to the length allowed them by that posture-as, for instance, equinus, by permitting the child to sit constantly with the foot hanging down.

Let us consider, in the former set of cases, what are the muscles whose paralysis (the antagonists remaining sound, or having regained power) would produce the different sorts of deformity.

\begin{tabular}{|c|c|c|}
\hline Sural muscles ... & & r Pes cavus. \\
\hline Anterior tibial ... $\ldots$ & & Clubfoot. \\
\hline Extensor longus digitorum ... & 0 & $\begin{array}{l}\text { 1st stage of varo- } \\
\text { equinus. }\end{array}$ \\
\hline Tibialis posticus & $\stackrel{8}{3}$ & 1st stage of valgus. \\
\hline $\begin{array}{l}\text { Sural muscles and deep flexors } \\
\text { Tibial. post. \& flexor long. digit. } \\
\text { Peronei . ... ... ... ... } \\
\text { Peronei with exten. long. digit. }\end{array}$ & 然 & $\begin{array}{l}\text { Calcaneus. } \\
\text { Valgus. } \\
\text { Varus. } \\
\text { Equino-varus. }\end{array}$ \\
\hline
\end{tabular}

It is conceivable, in theory, that more and other combinations of paralysed muscles may exist; in practice, I have only seen those above recorded.

I must also call especial attention to certain forms of lameness, which owe their existence to paralysis, yielding or almost passed away, which do not amount to deformity, although partaking of its nature, and, which are either the remnants or partially developed conditions of varus, valgus, pes carus, \&c. These conditions are not much noticed No. 2623. among the class of hospital patients, but are considered in the higher classes of society, especially among girls, as very detrimental. The most common of these is combined of two stages. The affected foot we will suppose on the ground, abnormally everted, and about to be advanced. In making this movement, the foot is at the instant rotated inwards, then in advancing is inverted, so that the backs of the toes touch or nearly touch the tibia of the opposite limb, the sole looking somewhat backward. In further projection forward a contrary impulse is given : the foot swings outwards, so that it falls to the ground everted and on its outer margin, and the sole only comes flat or nearly flat on the floor when some weight is placed on the limb. In this gait the leg is not advanced in a straight line, but describes an outward curve more or less sharp according to the severity of the case. This condition-not described, as far as I know, by any previous writer-I propose to term jactus internus; it depends upon paralysis, more or less severe, of the extensor longus digitorum and of the peroneus tertius. In the worst form the long and short peronei will also be found weak; hence the eversion is not produced by the muscles of the foot, but by the swing given to it by the circular. movement of the limb. A less common gait may be called jactus externus. Let us take up the description of the movement at the moment when the foot is about to be lifted from the ground and advanced. It stands at this time almost. straight or only slightly inverted. The heel lifts first, not straight, but with a swing inwards, as on a pivot round the toes resting on the ground. Thus the foot is in strong eversion, when the toes at last are lifted, too late in the rhythm of walking. The limb is then carried, not directly forward, but in a semicircle outward. In front the heel falls to the ground first, and checks ; while the front of the foot, continuing the circular jerk, swings inwards; so that, when in station again, the whole foot lies straight or somewhat inverted on the ground.*

The treatment of these cases must naturally vary with the particular form of lameness or deformity. Space will not permit me to deal with special directions, but the general plan remains the same whether we have to do with a distortion inwards or outwards.

First, the subject of tenotomy must engage our attention, and we must separate those conditions in which it may be desirable from those in which it is not permissible. In a former paragraph I have separated the deformity produced in a paralysed limb by position, in which cases the shortened muscle is as a rule paralysed and in a state of passive con tracture from the distortion produced by the active and tonic contraction of a muscle which, its antagonists being parilysed, is unopposed. The essential practical difference is evident: in the former case the shortened muscle has become a mere passive ligament-like cord; in the latter it is an active organ. Thus, in the one example to divide such a fibrous and degenerated band may be not only permissible, but necessary, and inflicts no injury on an organ already powerless; but in the other case to cut one of the few, perhaps the only, sound muscle of a limb is manifestly a blunder.

To distinguish between such degenerated muscles and those retaining some power of active contraction we may rely partly on our sense of touch, but chiefly on their behaviour under the galvanic stimulus (the constant current). In practice $I$ have never found it necessary to divide other tendons than the Achilles-sometimes the plantar fascia,for by the aid of chloroform I have always been able to stretch the others, and the cause of my objection to division of those tendons which lie behind the bones is, I believe, sufficiently known. ("Cure of Clubfoot.")

When, either by manual stretching or tenotomy if necessary, or without such means if possible, the foot is so released that the surgeon can without employment of very much power hold the limb at right angles to the leg, and the sole flat, his next indication is to apply some continuous force which can maintain such good position, and yet not absolutely prevent muscular action. On muscular action depends the possibility of cure. Elastic force is the only one that can fulfil these conditions. The various shoes with screws and fixed positions must, if they carry out their intention, override and prevent, and, according to the duration of their use, more or less destroy, muscular activity:

* This gait is occasionally one of the sequences of injudicious tenotomy. 
In cases of some severity the best method of applying elastic force is that introduced by me several years ago.* After a time, when the intensity of the malady has been subdued, or, in slighter cases, at once, the same sort of force can be applied by means of well-adapted shoes.

The great objection to the Scarpa shoe and the many slight modifications of it is, that the sole is in one piece and the screw-joint intended to act on the distortion is on a level with, and therefore affects the ankle, which joint is not at all distorted in by far the greater number of cases. Great credit is due to Dr. Lewis Sayre for his ingenuity in constructing a shoe divided in the middle of the sole (medio-tarsal joint), the front half connected with the posterior part by a ball-and-socket joint. The upper-leather of back and front of the foot is similarly separate; thus an india-rubber spring attached to the npper bar enables the surgeon to work on the front of the foot upwards, inwards, or outwards, according to the deformity. (See Fig. 1.)

Fia. 1.

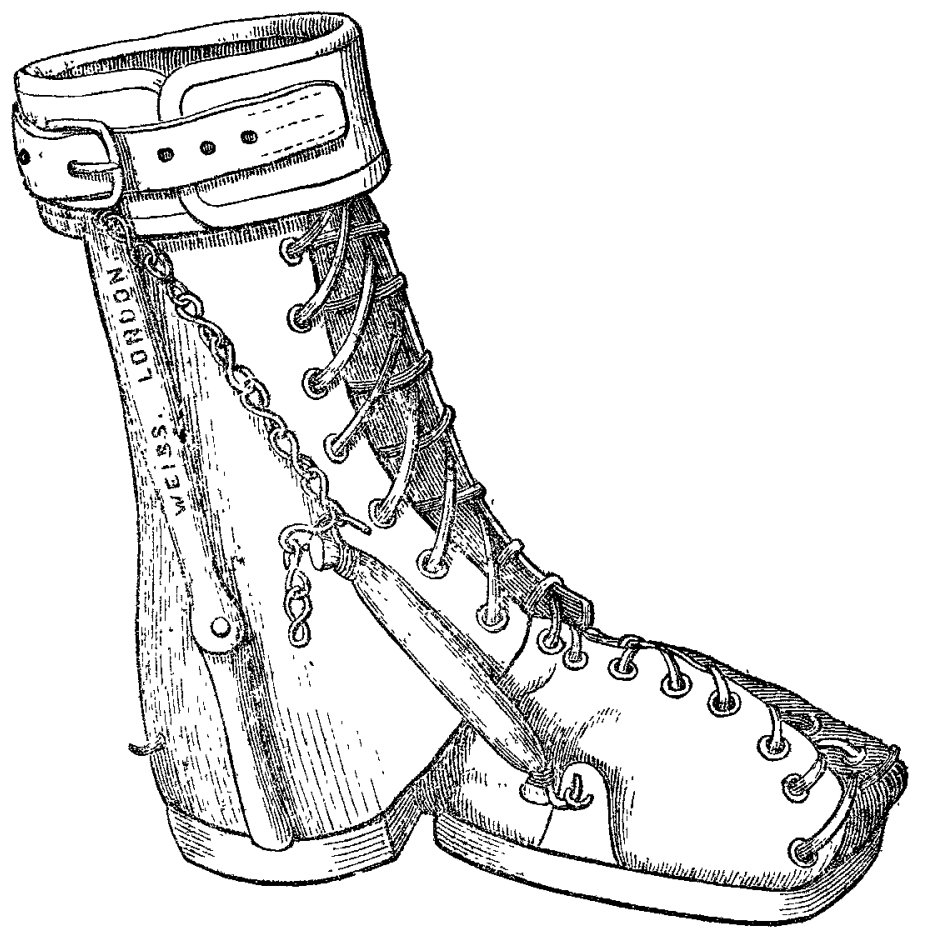

SAYRE SHOF, AS MODTHED. - On both sides of the ankle are hinged iron rods supporting calf band, and chain with india-rubber spring either for inside or outside of foot: on the outer side also another spring, running along the outer border of the sole, may be used to overcome adduction.

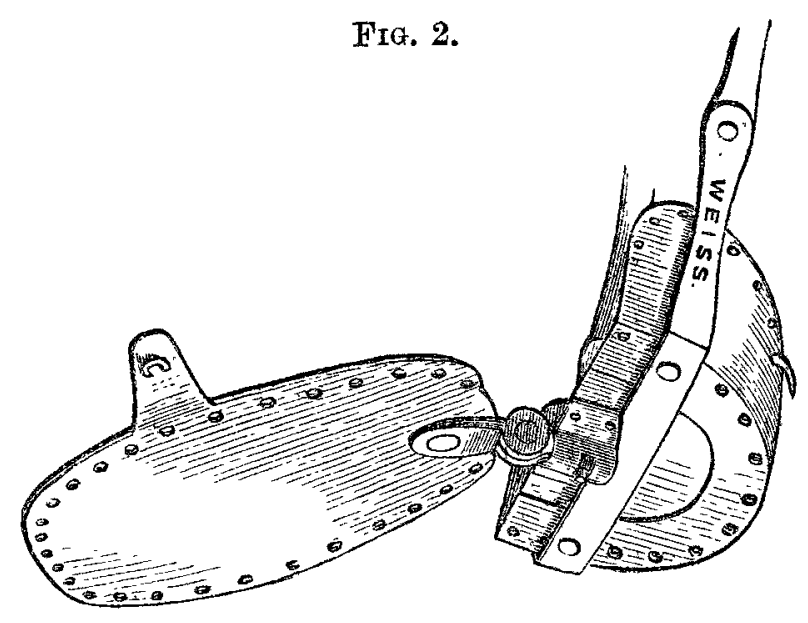

The sole of modified Sayre shoe, showing the three movements into which ball-and-socket movement is resolved : pivot (rotation) behind, flexion in middle, and adduction and abduetion in frotst.

I found that the ball of the joint in the original Sayre shoe, being somewhat bulky, was apt to wear out on the lower part, and the entire separation of the heel from the front of the foot permits water to enter and keep the stocking wet. To obviate the former inconvenience, I pro-

* This is much used in America by Dr. Lewis Sayre. In this country it has been much opposed, but has gained farour rapidly, $-\mathbf{R}, \mathbf{B}$, posed to resolve the compound movement of ball-and-socket joint into its three elements, and Messrs. Weiss have carried out for me that idea in the manner represented in Fig. 2 while at the same time Mr. Foveaux, of the above firm, adapted waterproof material as an inner lining to the junction of sole and heel, thus rendering the shoe watertight

The shoe thus modified-and I must beg my friend Dr. Sayre to pardon my making any change in his admirable inventions-answers every purpose extremely well, especially while a tolerably marked deformity, though not a severe one, still exists. It is especially adapted to the middle phase of clubfoot, and is by far the best instrument yet invented for the treatment of this disease. For cases less severe or further recovered I have invented the following apparatue, which, unlike most others, is worn inside an ordinary-looking boot, and attracts no attention to the limb. My patients thus walk in the street, and, the lame. ness being overcome, nothing unusual is observed.

Frg. 3.

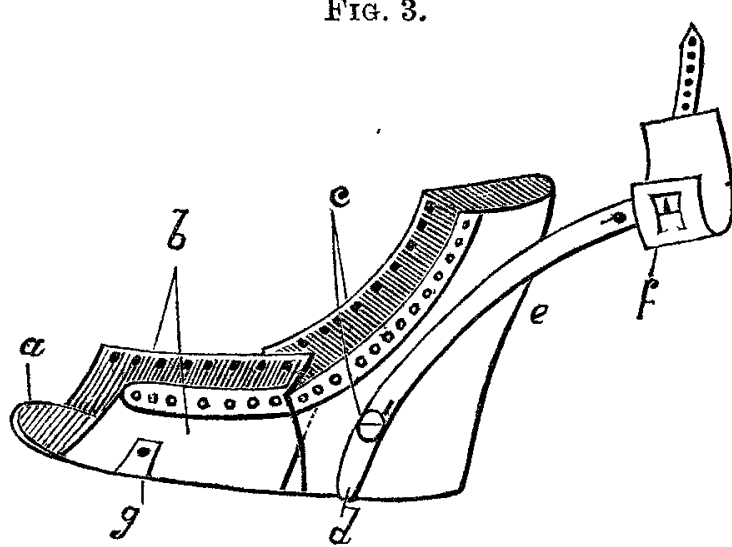

Burwatx's Inver Srot - $a$, Thin steel sole, covered with jean. $b$, Jean lappet for tarsus and metatarsus. $c$, Jean jean. b, Jean lappet for tarsus and metatarsus. c, Jean lappet for posterior tarsus and lower leg. $b$, hever with hinge at top. $e$, spen anklet. y, Tong

The sole is made of steel, of spring temper, rather thicker than a calling card, jointed in the medio-tarsus for abduction and adduction only, and that merely for those cases where necessary. Eversion or inversion, flexion and extension, are produced by the bend and twist of the steel sole. The lappets for lacing are of a strong cotton material. From the heel on the outer side runs upward a metal rod to a level with the ankle-joint, at which point is hinged, in the sense of flexion and extension, a steel spring, connected above to a calf piece. This spring is to be bent outward or inward, according as the case is valgus or varus.

To put on this shoe its whole sole is to be turned, so as to fit on the sole of the foot, and the front part twisted inward or outward, as necessary for either deformity, so that while the sole of the shoe is fitted and adapted to that of the foot, the front lappet is laced; and then, while still keeping, by manual pressure, the shoe-sole fitted, the back lappet is also laced. This being completed, the steel spring is brought to the leg, and the calf-piece adapted, while the shoe-sole and front of the apparatus is released. By this means every part of the foot is subject to spring pressurethe front to the bend and twist of the spring sole, the back to the action of the vertical spring. Besides this, however, and to supplement any deficient force, india-rubber springs are stretched from the calf-piece to the sole; and, if necessary, an abduction-spring is carried along the outer side. All this apparatus is concealed by an ordinary boot, if for a boy wearing trowsers; if for one wearing knickerbockers, or for a girl, the boot called "polonaise," coming higher on the leg, may be used.

This form of mechanical shoe I have found very valuable in the cases of lameness I have described as jactus internus and externus; also in cases of paralytic clubfoot in the stage of recovery. Of course, with all and every of the contrivances above described, patient and persistent galvanism, as also injection of strychnia, must be employed.

THE North-Eastern Hospital for Children, Hackneyroad, has received $\$ 200$ under the will of $\mathbf{M r}$. Charles Pease. 